\title{
PVAT AND ATHEROGENESIS: A CROSSROAD OF WHITE AND BROWN ADIPOBIOLOGY
}

\author{
Gorana Rančić ${ }^{1}$, Marco Fiore ${ }^{2}$, Neşe Tunçel ${ }^{3}$, Marcia Hiriart ${ }^{4}$, Jerzy Beltowski ${ }^{5}$, Luigi Aloe ${ }^{2}$, and \\ George N. Chaldakov ${ }^{6}$
}

'Department of Histology and Embryology, Medical Faculty, Niš, Serbia, ${ }^{2}$ Institute of Cell Biology and Neurobiology, National Research Council (CNR), Rome, Italy, ${ }^{3}$ Department of Physiology, Eskişehir Medical University, Eskişehir, Turkey, ${ }^{4}$ Institute of Cell Physiology, Universidad Nacional Autónoma de México, Mexico City, Mexico, ${ }^{5}$ Department of Pathophysiology, Medical University, Lublin, Poland, and ' ${ }^{6}$ Laboratory of Cell Biology, Department of Anatomy and Histology, Medical University, Varna, Bulgaria

Two roads diverged in a wood, and I -

I took the one less traveled by,

And that has made all the difference.

\section{Robert Frost, The Road Not Taken}

In 1999, the prevailing response-to-injury hypothesis of Russell Ross stated that atherosclerosis is an inflammatory disease, leading - through an inside-out road - to endothelial and smooth muscle dysfunction resulting in the formation of atherosclerotic plaques (reviewed in 1). Accordingly, intima-media thickness became an accepted measure of structural vascular remodeling and a strong predictor of atherosclerosis. However, it is unlikely that such a road may solely travel the whole multiplex network like that of atherogenesis. Recently things changed dramatically and the attention was moved from inside-out to outside-in road emphasizing the role for adventitial and adipose dysfunction in the processes of atherogenesis $(2,3)$.

There are two major types of adipose tissues, white adipose tissue (WAT) and brown adipose tissue (BAT). Anatomically, WAT comprises two major depots, subcutaneous and visceral, and multiple small depots around internal organs (Fig. 1). On the other hand BAT is localized around kidney, adrenal, pancreas, liver and neck, as well as the thoracic aorta (perivascular adipose tissue, PVAT) and the epicardium (epicardial adipose tissue, EAT) $(4,5)$.

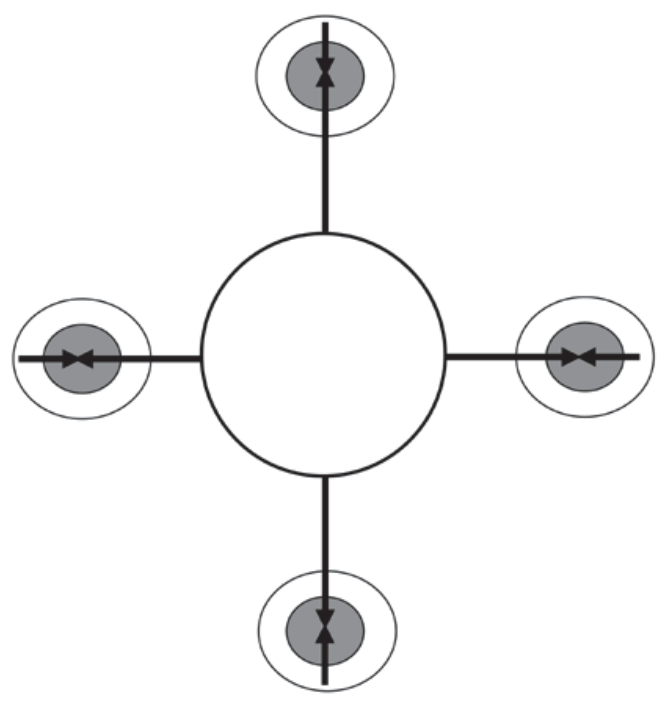

Figure 1. Schematic illustration of a large adipose depot (visceral and subcutaneous adipose tissue shown as one big circle in the middle) and small adipose depots (organ-associated adipose tissue shown as small circles at the periphery). Endocrine action (long arrows) and paracrine action (short arrows) of adipokines, lipokines and other adipose-derived signals on various organs. Organ parenchyma (grey) is surrounded by adipose tissue (white). From (20). 
Adipose tissue remodeling (phenotypic modulation) is a complex process that allow adaptation to external changes (reviewed in 5). A deeper understanding of this phenomenon may give better insights in the pathogenesis of obesity and related cardiometabolic diseases. And may facilitate the development of therapeutic modalities for them.

The modulation of PVAT from brown/thermogenic to white/ proinflammatory phenotype is highlighted at an epigenetic level by Karl Blirando in his state-of-the-science (SOS) review published in this volume of Adipobiology (6). Regarding PVAT we prefer the term tunica adiposa (7, 8; Fig. 2) or periadventitial adipose tissue (PAAT) as a path to atherogenesis (9).

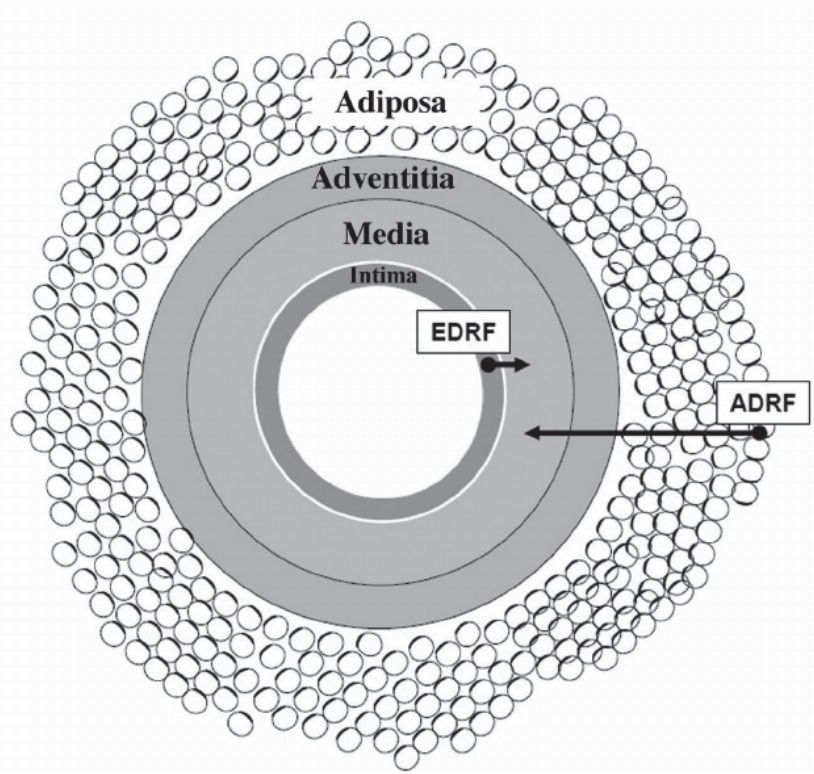

Figure 2. Schematic presentation of a cross-sectioned arterial wall consisted of tunica intima, tunica media, tunica adventitia and tunica adiposa. Adipose dysfunction is mediated by an unbalanced secretion of pro- and anti-inflammatory adipokines and lipokines, also an inhibition of the release of adipose-derived relaxing factors (ADRF), such as NO (10) and $\mathrm{H}_{2} \mathrm{~S}$ (11). EDRF, endothelium-derived relaxing factor. From (8).

We learn from Blirando's SOS that many factors associated with epigenetic signals are pivotal for a brown-to-white transition and, in turn, the metabolic syndrome and atherosclerosis. A large number of regulators at critical genes set up specific patterns of DNA methylation and histone phosphorylation, acetylation and/or methylation, which act as an epigenetic code to modulate the correct progress of adipocyte transition form BAT to WAT, a process termed PVAT whitening. The latter is a sort of outward remodeling, a pathological process triggered by a high fat diet and/or inflammation. Blirando's SOS highlights the epigenetic regulation of PVAT's expression of key biomolecules involved in the control of metabolism and inflammation such as AMP-activated protein kinase (AMPK), sirtuin 1 (SIRT1), adiponectin, leptin and nerve growth factor (NGF); see Fig. 2 of (6).

According to most reports PVAT is found around vessels of large and medium size. In 1991, Soltis and Cassis reported for the first time that PVAT has an anti-contractile effect (12). Healthy PVAT is generally characterised by the degree of its thermogenic, anti-contractile and anti-inflammatory function. The loss of these properties is regarded as a dysfunction of PVAT. Whereas ontogeny defines PVAT localization around blood vessels, the main determinant of PVAT phenotype in adulthood seems to be the local environmental factors as illustrated in Blirando's figure $1 \mathrm{~A}, \mathrm{~B}(6)$.

Today's paradigm says that atherosclerosis mainly occurs in arteries surrounded by white PVAT (Fig. 3). There is not a clear division of pure BAT or pure WAT in both PVAT and EAT. Plasticity and infiltration of brown adipocytes in WAT may lead to the formation of brite adipose tissue (brown in white). Accordingly, beige or brite adipocytes are newly identified type of brown adipocyte distinct from the classical brown adipocyte that makes up the interscapular thermogenic organ of other mammals (4, 6, 13 for PVAT, 4, 5, 14 for EAT).

Until recently, physicians have looked upon obesity and related diseases as an accumulation of external adipose tissue (subcutaneous and abdominal). This was routinely evaluated by anthropometric measurements including BMI and waist, hip and, recently, neck circumference. However, recent data using noninvasive imaging, such as echography, computed tomography, MRI and positron emission tomography, reveal a new picture of adipotopography. We should therefore focus our attention not only on anthropometric values of external adipose tissue, but - more importantly - the "weight" of internal, organ-associated adipose tissue, including PVAT/tunica adiposa. Thin outside, fat inside (TOFI) and other phenotypes of adipose distribution are based on imaging data (17) and illustrated in Table 1 herein.

Table 1. Adipotopography - variations+

\begin{tabular}{|c|c|}
\hline TOFI** & thin outside, fat inside \\
\hline TOTI***** & thin outside, thin inside \\
\hline $\mathrm{FOFI}^{*}$ & fat outside, fat inside \\
\hline FOTI*** & fat outside, thin inside \\
\hline
\end{tabular}

+ The number of asterisks indicates quality, here - the quality of cardiometabolic health, as related to adipose tissue distribution. TOTI represents a highest, whereas FOFI the lowest quality of cardiometabolic health. 


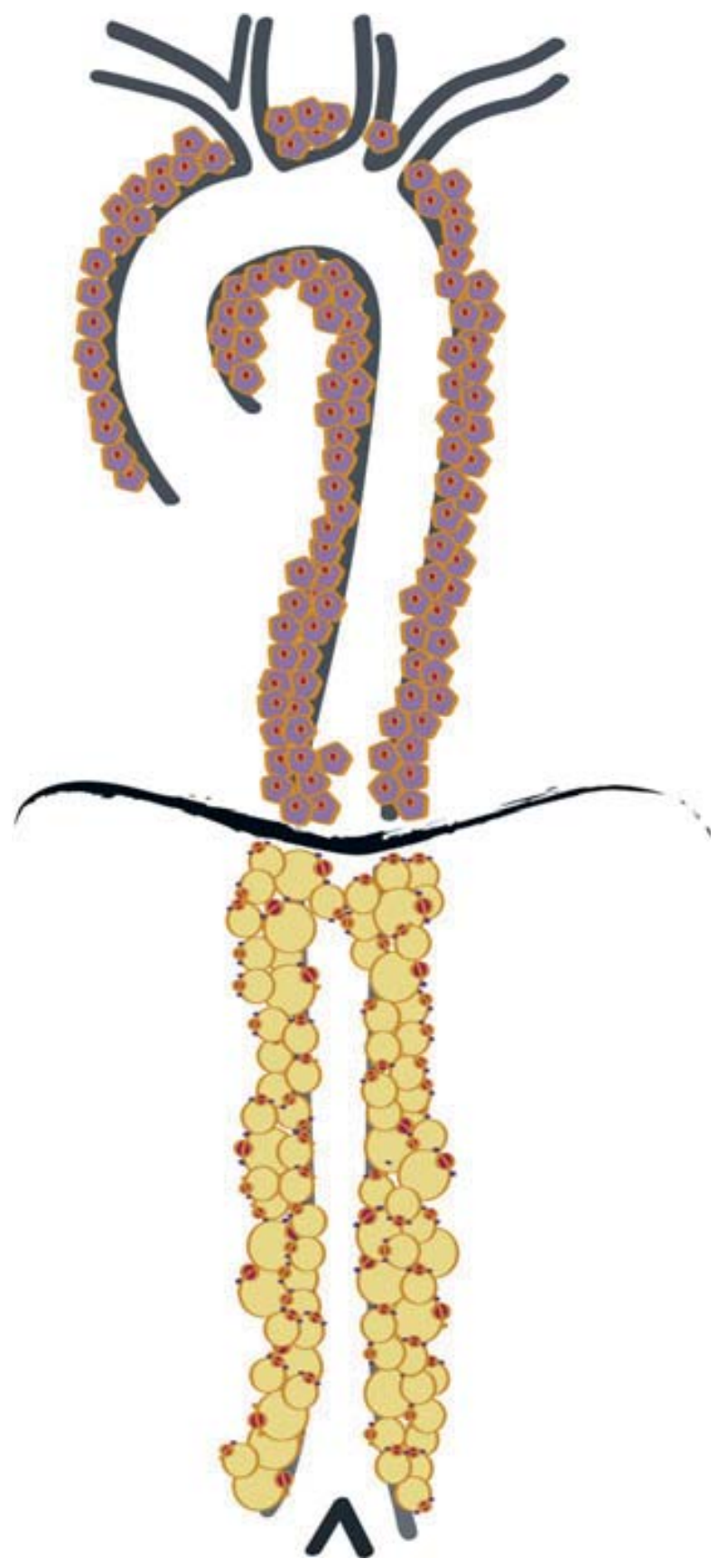

Figure 3. Regional differences in periaortic perivascular adipose tissue (PVAT) are related to distinct functions and pathological complications. The differences in PVAT might also appear within different regions of the same vessel, as schematically illustrated herein. Aortic arch and thoracic aorta are surrounded by brown adipose tissue, whereas abdominal aorta by white adipose tissue. It may be brown PVAT which makes thoracic aorta resistance to high-fat feeding thus protecting the artery wall against atherosclerosis. Contrary, white PVAT is highly responsive to high-fat diet and thus being prone to the development of atherosclerosis. Modified from (13).
As we stated in 2000, it is imperative that "to further elucidate the vascular function, we should no longer, as hitherto, cut PAAT from the vascular wall, but keep it attached and in place, and subject to thorough examination" (2; updated in $4-6,15$, $16,18,19)$. And that has made some difference, paraphrasing Robert Frost.

Yet, at least one question remains unanswered: could the concept of PVAT/EAT whitening $(4,6,14,18,19)$ also work in adipose tissue surrounding other internal organs (Table 2).

Table 2. Examples of adipoparacrinology of diseases. From (20).

$\begin{array}{ll}\text { (i) } & \text { Epicardial adipose tissue and cardiometabolic } \\ & \text { diseases } \\ \text { (ii) } & \text { Periadventitial adipose tissue (tunica adiposa) and } \\ & \text { atherosclerosis } \\ \text { (iii) } & \text { Mesenteric adipose tissue and Crohn's disease and } \\ & \text { ulcerative colitis } \\ \text { (iv) } & \text { Peripancreatic adipose tissue and type } 2 \text { diabetes } \\ & \text { mellitus } \\ \text { (v) } & \text { Mammary gland-associated adipose tissue and breast } \\ & \text { cancer } \\ \text { (vi) } & \text { Periprostatic adipose tissue and prostate cancer } \\ \text { (vii) Lymph node-associated (perinodal) adipose tissue } \\ \text { and HIV-associated adipose redistribution syndrome } \\ \text { (HARS) } \\ \text { (viii) }\end{array}$

\section{Acknowledgements}

We thank the National Research Council, Rome, Italy for a continuing financial support. We apologize to the authors of many relevant articles that were not quoted here for reason of brevity.

\section{Conflict of interest statement}

The authors have no conflicts of interest. 


\section{References}

1. Ross R. Mechanisms of disease: Atherosclerosis - an inflammatory disease. N Engl J Med 1999; 340: 115-126. DOI: 10.1056/NEJM199901143400207

2. Chaldakov GN, Fiore M, Ghenev PI, Stankulov IS. Aloe L. Atherosclerotic lesions: possible interactive involvement of intima, adventitia and associated adipose tissue. Int Med J 2000; 7: 43-49.

3. Chaldakov GN, Fiore M, GhenevI, Beltowski J, Rancic G, Tunçel N, Aloe L. Triactome: neuro-immune-adipose interactions. Implication in vascular biology. Front Immunol 2014 March. DOI: 10.3389/fimmu.2014.00130

4. Sacks H, Symonds ME. Anatomical locations of human brown adipose tissue. Functional relevance and implications in obesity and type 2 diabetes. Diabetes 2013; 62: 17831790. DOI: $10.2337 / \mathrm{db} 12-1430$

5. Choe SS, Huh JY, Hwang IJ, Kim JI, Kim JB. Adipose tissue remodeling: Its role in energy metabolism and metabolic disorders. Front Endocrinol 2016; 7: 30. DOI: 10.3389/fendo. 2016.00030

6. Blirando K. Epigenetic regulation of adipocytes phenotype: implication for perivascular adipose tissue contribution to cardiometabolic diseases. Adipobiology 2016; 8: 4-26.

7. Chaldakov GN, Beltowsky J, Ghenev PI, Fiore M, Panayotov P, Rancic G, Aloe L. Adipoparacrinology - vascular periadventitial adipose tissue (tunica adiposa) as an example. Cell Biol Int 2012; 36: 327-330. DOI:10.1042/CBI20110422

8. Chaldakov GN, Fiore M, Ghenev PI, Tunçel N, Rančić G, Atanassova P, Aloe L. State-of-the-artery: Periadventitial adipose tissue (tunica adiposa). Biomed Rev 2009; 20: 41-44.

9. Stankulov IS, Aloe L, Ghenev PI, Manni L, Pavlov P, Fiore M, et al. PAAT: a path to atherosclerosis? Biomed Rev 2002; 13: 63-65.

10. Tunçel N, Peker E, Şener E, Dal AG, Tunçel M, Chaldakov $\mathrm{GN}$, et al. Cold exposure and adipose nitric oxide and mast cells: influence on aorta contractility. Adipobiology 2009; 1: $67-75$
11. Wojcicka G, Jamroz-Wisniewska A, Attanasova P, Chaldakov GN, Chylinska-Kula B, Beltowski J. Differential effects of statins on endogenous $\mathrm{H}_{2} \mathrm{~S}$ formation in perivascular adipose tissue. Pharmacol Res 2011; 63: 68-76. DOI: 10.1016/j.phrs.2010.10.011

12. Soltis EE, Cassis LA. Influence of perivascular adipose tissue on rat aortic smooth muscle responsiveness. Clin Exp Hypertens A 1991; 13: 277-296.

13. Gil-Ortega M, Somoza B, Huang Y, Gollasch M, FernandezAlfonso MS. Regional differences in perivascular adipose tissue impacting vascular homeostasis. Trends Endocrinol Metab 2015; 26: 367-375. DOI: 10.1016/j.tem.2015.04.003

14. Sacks HS, Fain JN, Bahouth SW, Ojha S, Frontini A, Budge $\mathrm{H}$, et al. Adult epicardial fat exhibits beige features. J Clin Endocrinol Metab 2013; 98: E1448-1455. DOI: 10.1210/ jc. 2013-1265.

15. Nava E, Llorens S. The paracrine control of vascular motion. A historical perspective. Pharmacol Res 2016; 113: 125-145. DOI: $10.1016 /$ j.phrs.2016.08.003

16. Ayala-Lopez N, Watts SW. New actions of an old friend: perivascular adipose tissue's adrenergic mechanisms. $\mathrm{Br} \mathrm{J}$ Pharmacol 2016. DOI: 10.1111/bph.13663.

17. Thomas EL, Parkinson JR, Frost GS, Goldstone AP, Dore CJ, Mc-Carthy JP, et al. The missing risk: MRI and MRS phenotyping of abdominal adiposity and ectopic fat. Obesity (Silver Spring) 2012; 20:76-87. DOI: 10.1038/oby.2011.142

18. Chechi K, Carpentier AC, Richard D. Understanding the brown adipocyte as a contributor to energy homeostasis. Trends Endocrinol Metab 2013; 24: 408-420. DOI: 10.1016/j. tem.2013.04.002

19. Chechi K, Nedergaard J, Richard D. Brown adipose tissue as an anti-obesity tissue in humans. Obes Rev 2014; 15: 92-106. DOI: 10.1111/obr.12116

20. Chaldakov GN, Tunçel N, Beltowski J, Fiore M, Ranćić G, Tonchev A, et al. Adipoparacrinology: an emerging field in biomedical research. Balkan Med J 2012; 29: 2-9. DOI: 10.5152/balkanmedj.2012.022 